\title{
Design of Output-Input Inversed Polarity Pulse Power Divider for Ultra-Wideband Communications
}

\author{
Yufu Li $\mathbb{D}$ and XiaoXing Yin $(\mathbb{D}$ \\ State Key Laboratory of Millimeter Waves, Southeast University, Nanjing 210096, China \\ Correspondence should be addressed to Yufu Li; yufu@awrcorp.com
}

Received 29 January 2018; Accepted 5 April 2018; Published 17 May 2018

Academic Editor: Maode Ma

Copyright (C) 2018 Yufu Li and XiaoXing Yin. This is an open access article distributed under the Creative Commons Attribution License, which permits unrestricted use, distribution, and reproduction in any medium, provided the original work is properly cited.

\begin{abstract}
The implementation of a output-input inverse polarity pulse power divider based on the use of a SMA directly feed asymmetric coplanar stripline phase inverter for ultra-wideband communication is proposed. The novelty of the proposed power divider can be demonstrated that the electromagnetic energy guided by the CPW divides naturally into the slots of two asymmetric coplanar striplines and the polarity of the input pulse be reversed by asymmetric coplanar stripline to SMA transition. SMA connectors are mounted directly to the output asymmetric coplanar striplines and seven pairs of metal rods are soldered vertically to the substrate with seven resistors on top for improving the isolation and matching performance. The simulated and measured result in frequency domain agree well showing equal power division with less than $2 \mathrm{~dB}$ of additional insertion loss and in-phase for the outputs ports across the desired band of $0.4 \mathrm{GHz}$ to $4.0 \mathrm{GHz}$ (one decade) which indicates an ultra-wideband feature. The return loss for all the ports and the isolation between the two output ports are better than $10 \mathrm{~dB}$ which demonstrates good matching and isolation performance. To illustrate the short pulse performance of the proposed power divider, Inverse Fourier Transformation is used to calculate the input and output signals. The Gaussian pulse with a $-10 \mathrm{~dB}$ bandwidth is utilized as the stimulus signal and the port signals in time domain are derived from the measured scattering parameters and discussed. Time domain results show that the same magnitude of the pulse is obtained between the two outputs and the polarity of the output pulse has been inversed compared to the input one. Simulated and measured results in both frequency and time domain agree well and show the feasibility and validity of the proposed power dividers.
\end{abstract}

\section{Introduction}

Power dividers are one of the key components in ultrawideband systems and have been widely used in balanced mixers, balanced amplifiers, antenna feeding networks, and modulation systems. With the rapid development of ultrawideband wireless communications, various forms of power dividers with output to input and output to output in-phase have been proposed by using microstrip line, stripline, and substrate integrated waveguide [1-8]. However, equal-split and output-input inverse polarity but output-output in-phase power divider are also greatly needed in the modulation system. Moreover, the coupled structures or the transition between different types of the transmission lines need to be carefully manipulated to avoid mismatching and multilayer PCB is expensive to be fabricated [9-12].

Coplanar stripline is a uniplanar balanced transmission line which is widely used in out-of-phase power dividers, baluns, balanced mixers, and phase shifters. For out-of-phase applications, a microstrip line to coplanar stripline transition is widely applied. To enlarge its working frequency, loading components are commonly needed which add complexity and loss inevitably. Apart from these, the slot width in the conventional coplanar stripline is too narrow to get low characteristic impedance [13] which places a high demand on the traditional PCB manufacture crafts.

In this article, a novel ultra-wideband horizontal polarized with equal-split, output-input inverse polarity but output-output in-phase power divider based on the use of a SMA directly feeding asymmetric coplanar stripline phase inverter is presented. The new structure is based on mixing two different transmission lines, namely, the coplanar waveguide (CPW) and asymmetric coplanar stripline, both with metallic vias which can help improve the characteristic impedance performance and, thus, can be feed directly by 


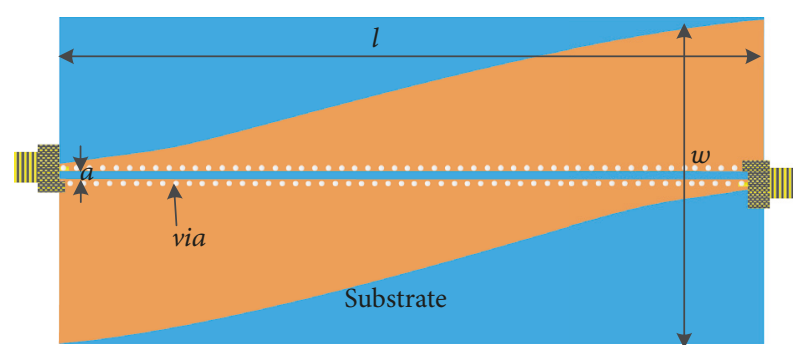

(a)

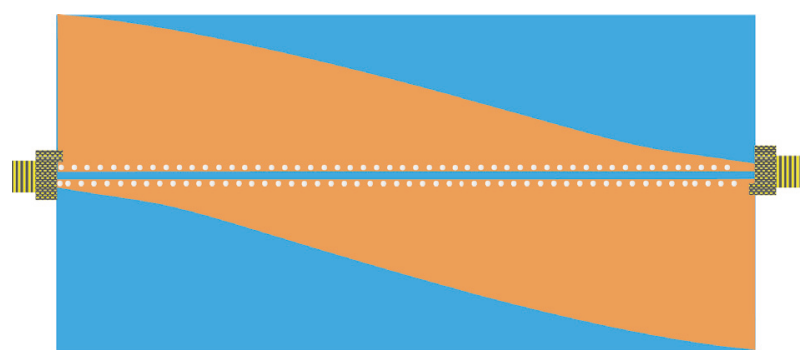

(b)

FIGURE 1: The asymmetric coplanar stripline phase inverter fed by SMA directly. (a) top view and (b) bottom view.

SMA connectors. A CPW is used for the input and division section, while two asymmetric coplanar striplines are used for the output section. Electromagnetic energy guided by the two slots of CPW is divided naturally into the slots of the asymmetric coplanar stripline, which makes it a wideband operation. Asymmetric coplanar stripline to SMA transition is utilized for polarity inverse. Seven pairs of metal rods are soldered perpendicularly to the surface of the ground, facilitating the installation of the isolation resistors. Based on the novel structure, the prototype power divider with single-layer PCB is fabricated and measured. The simulated and measured result in both frequency and time domain agrees well and demonstrates the feasibility and validity of the proposed power dividers.

\section{Phase Inverter and Power Divider Geometry and Design}

For the realization of the phase inverter, the asymmetric coplanar stripline to SMA transition is applied in this paper. SMA connectors are soldered directly on the asymmetric coplanar stripline as shown in Figures 1(a) and 1(b), respectively. The characteristic impedance of the asymmetric coplanar stripline can be lowered by the metallic vias and is utilized for ease of matching to 50 ohms coaxial connectors.

The proposed power divider in this paper is composed of CPW and asymmetric coplanar stripline which are suitable for planar power divider design and the electric field is parallel to the ground which makes it a solution for multipolarization antenna and its feeding system. For the proposed power divider, the input section and the division section are realized as CPW transmission line, while the output sections are realized as asymmetric coplanar stripline with $50 \mathrm{Ohms}$ characteristic impedance. The coplanar waveguide

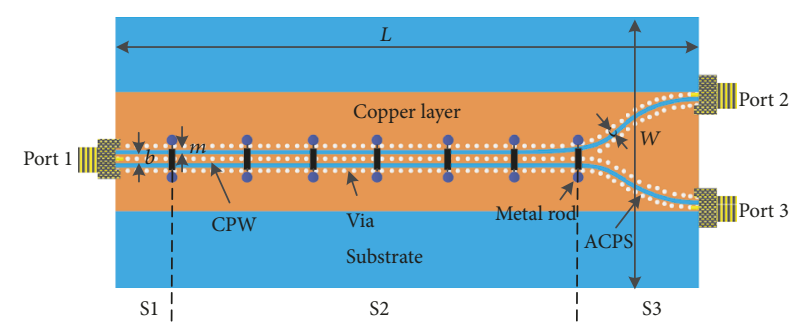

(a)

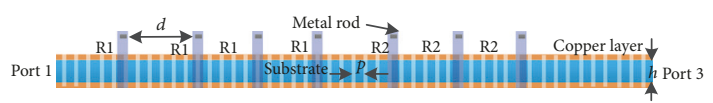

(b)

FIgURE 2: The proposed output-input inversed polarity power divider. (a) Top view and (b) side view.

TABLE 1: Parameters of the phase inverter and the proposed power divider (dimensions in $\mathrm{mm}$ and resistor values in Ohms).

\begin{tabular}{lccccccc}
\hline$a$ & 0.27 & $b$ & 0.57 & $d$ & 15 & $W$ & 60 \\
$w$ & 15 & $m$ & 0.3 & $p$ & 0.8 & $R 1$ & 220 \\
$l$ & 31 & $c$ & 0.27 & $L$ & 150 & $R 2$ & 330 \\
\hline
\end{tabular}

and the asymmetric coplanar striplines are printed on both sides of a substrate. The geometries on both sides are exactly the same and are connected by metallic vias. As CPW can be approximately regarded as a parallel structure of two asymmetric coplanar striplines running side by side; thus, the incident electromagnetic energy at the input section which is guided along the two slots of the coplanar waveguide can be equally and naturally divided into the two slots in the division and output sections.

The top and side views of the proposed power divider based on the CPW and asymmetric coplanar stripline are shown in Figures 2(a) and 2(b), respectively.

\section{Simulated and Experimental Results}

The phase inverter and the proposed power divider have been analyzed and fabricated on the Rogers $4003 \mathrm{C}$ with a thickness of $0.813 \mathrm{~mm}\left(\varepsilon_{r}=3.55, \tan \delta=0.0027\right)$ to verify its performance in both frequency and time domain. The central frequency for the proposed power divider is chosen as $2.2 \mathrm{GHz}$ and port characteristic impedance is 50 Ohms. Parameters of the phase inverter and the proposed power divider are calculated and optimized using Analyst [14] and time domain results are obtained using Visual System Simulator from AWR Corporation, A National Instruments Company. All the dimensions are shown in Table 1.

Figure 3 shows, respectively, the photos of the fabricated phase inverter based on the using of asymmetric coplanar stripline to SMA transition.

Figure 4 shows, respectively, the top and bottom side photograph of the proposed power divider.

Measurements were carried out using Agilent N5230C network analyzer and SMA connectors were used to connect the phase inverter to the instrumentation directly. Figure 5 


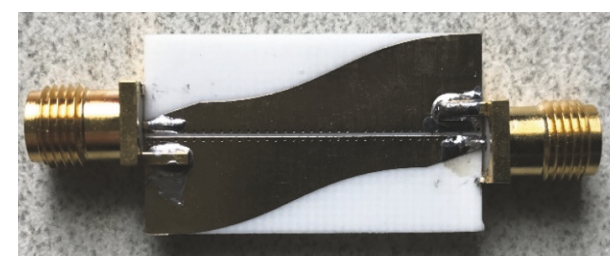

(a)

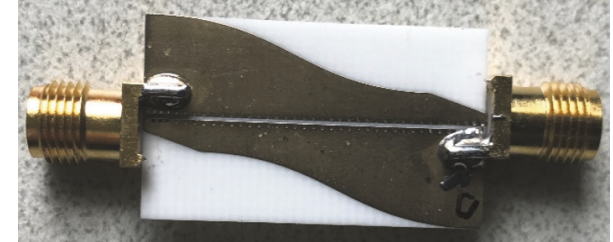

(b)

FIgURE 3: Photos of the fabricated phase inverter. (a) Top view and (b) bottom view.

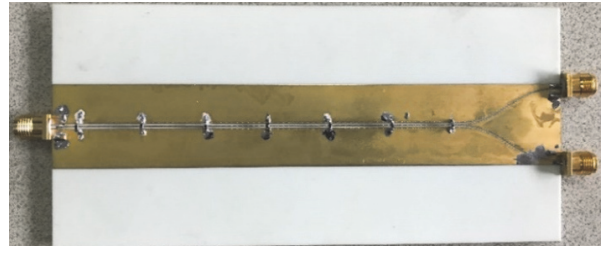

(a)

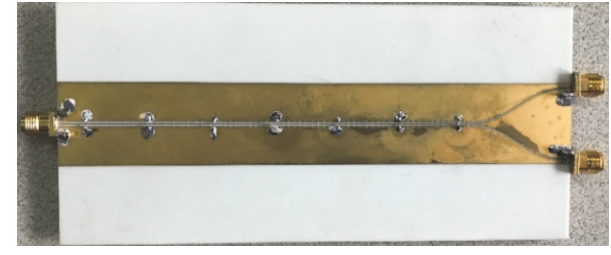

(b)

FIgURE 4: Photos of the fabricated power divider. (a) Top view and (b) bottom view.

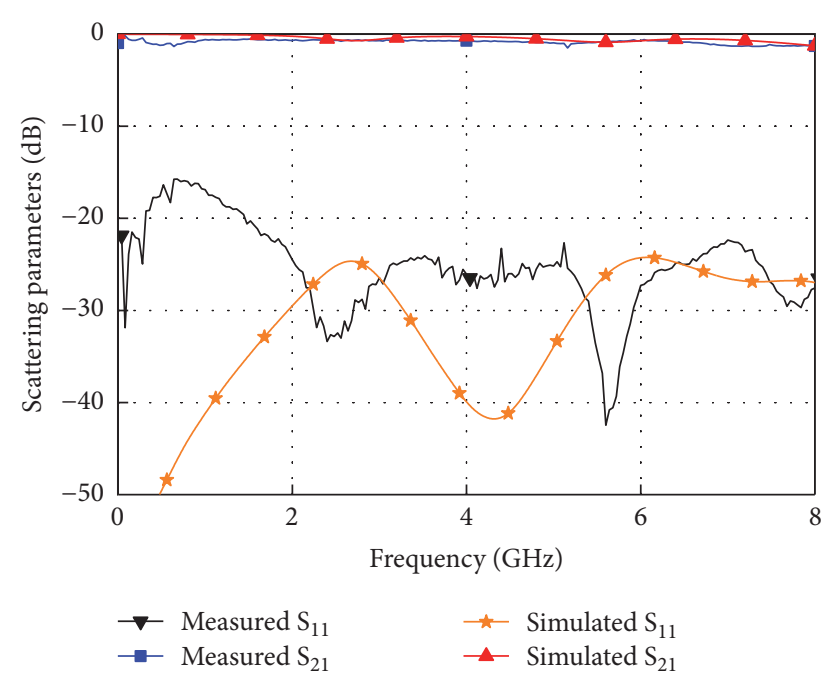

FIGURE 5: The simulated and measured performance of the phase inverter in frequency domain.

shows the simulated and measured performance of the manufacture phase inverter. It is observed that the phase inverter works well from $9 \mathrm{KHz}$ to $8 \mathrm{GHz}$. Both the simulated and measured insertion loss is less than $1.5 \mathrm{~dB}$ and the return loss is more than $16 \mathrm{~dB}$ across the whole the working frequency band.

Time domain characterization is an attractive description method for ultra-wideband pulse phase inverter. For the time domain pulse application, Inverse Fourier Transformation (IFT) is used to calculate the input and output signal. The Gaussian pulse with a $-10 \mathrm{~dB}$ bandwidth from $\mathrm{DC}$ to $8 \mathrm{GHz}$ is utilized as the stimulus signal and is expressed as

$$
G(t)=\exp \left(-\frac{4 \pi\left(a-a_{0}\right)^{2}}{m^{2}}\right),
$$

where $a_{0}$ equals $0.21 \mathrm{~ns}$ and $m$ is $0.22 \mathrm{~ns}$.
The spectrum of the Gaussian pulse is denoted by $G(f)$. The Gaussian pulse shown in (1) is used to calculate the pulse waveforms along with the measured scattering parameters. The outgoing pulse signal $b_{k i}(t)$ is derived as follows:

$$
b_{k i}(t)=\operatorname{IFFT}\left[G(f) \cdot S_{k i-m}(f)\right],
$$

where $S_{k i-m}(f)$ represents the measured scattering parameters of the fabricated ultra-wideband pulse phase inverter.

To illustrate the short pulse performance of the proposed ultra-wideband pulse phase inverter, port signals in time domain derived from the measured scattering parameters are depicted in Figure 6 along with simulated results. It is observed that the measured time domain signals are almost the same as the simulated ones. Compared to the input signal, the polarity of the output signal is inverted. It is also seen that the peak value of the reflected signal is lower than 0.08 and the trailing pulse after $0.7 \mathrm{~ns}$ is quite small, which also indicates the good impedance matching of ultra-wideband pulse phase inverter. Both the simulated and measured results match well.

Figure 7 shows the simulated and measured performance of the proposed power divider. It is observed from Figure 7(a) that the power divider operates at a center frequency of $2.2 \mathrm{GHz}$ with more than $10 \mathrm{~dB}$ isolation across the desired frequency band from $0.4 \mathrm{GHz}$ to $4 \mathrm{GHz}$. As it is well known, the input power is equally divided into the output ports in theory; that is, $S 21=S 31=-3 \mathrm{~dB}$; thus only $S 21$ is depicted in the Figure $7(\mathrm{a})$; the measurement shows that the proposed power divider has a maximum $2 \mathrm{~dB}$ of additional loss. All the return loss for the input port and output ports of the proposed power divider is better than $10 \mathrm{~dB}$ which demonstrates good matching performance. Besides, both of the simulated and measured amplitude and phase imbalance are shown in Figure 7(b). It is shown that the amplitude imbalance between the two output ports is less than $0.2 \mathrm{~dB}$ and they are in-phase which only has less than 4 degrees phase difference across the working frequency band. On the whole, all the measured 


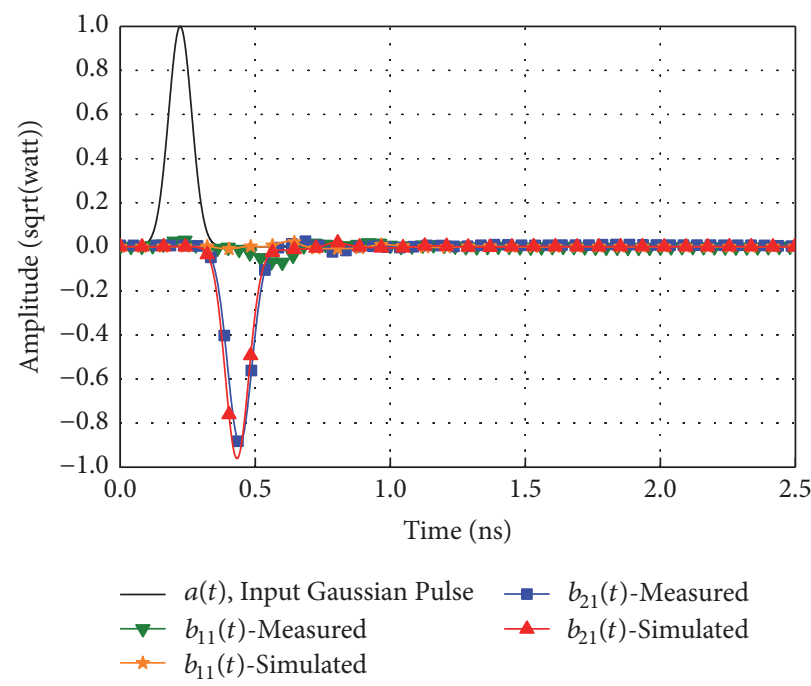

FIGURE 6: The simulated and measured performance of the phase inverter in frequency domain.

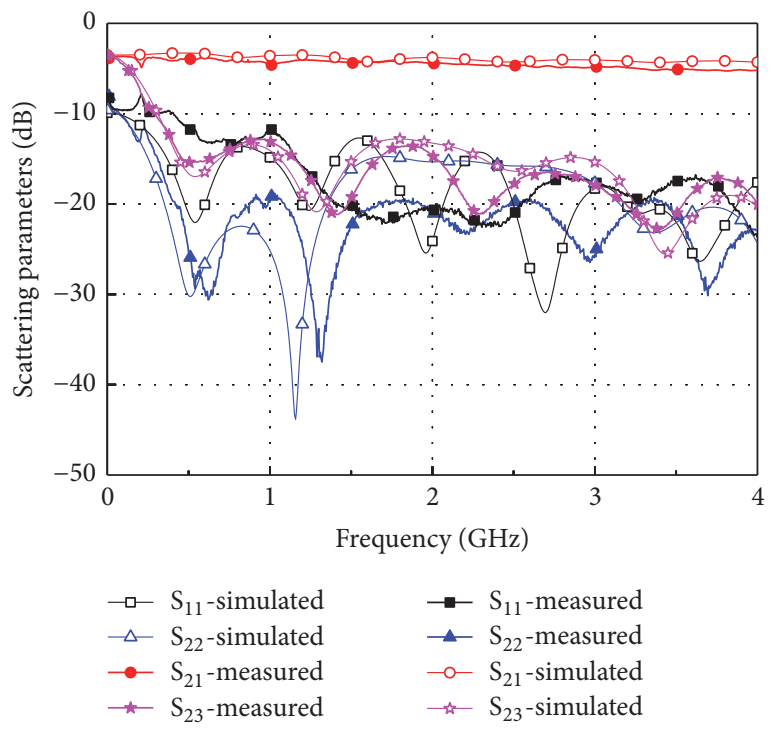

(a)

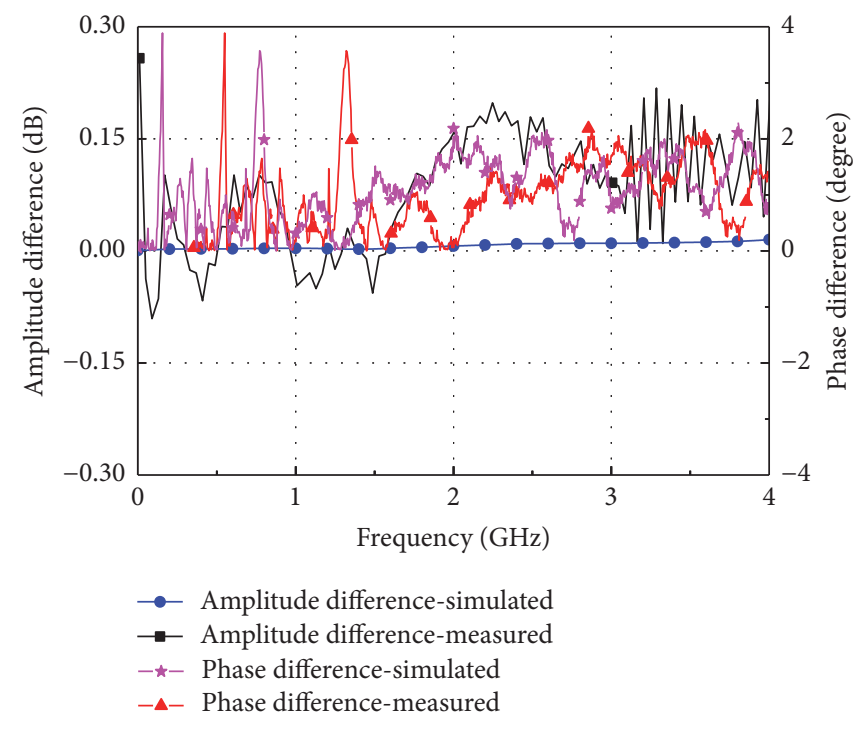

(b)

FIGURE 7: The simulated and measured performance in the frequency domain. (a) The simulated and measured $S$-parameters and (b) the simulated and measured amplitude and phase imbalance of the output ports.

results agree well with the simulated ones, demonstrating the feasibility and validity of the proposed power divider.

Time domain results are calculated and shown in Figure 8. Figure 8(a) shows that, compared to the input signal, reflection signals at port 1 and port 2 are quite small, while the transmission signals from port 2 to port 3 are very small too which comply with isolation results in the frequency domain. According to Figure 8(b), the output pulses at port 2 have inversed polarity waveform compared to the input signal at port 1. It is observed from Figure 8 that measured time domain signals are almost the same as the simulated ones.

The comparison between the proposed power divider and other referenced works is presented in Table 2 . The bandwidth is defined when $S 32$ is less than $-10 \mathrm{~dB}$. Firstly, The design presented in $[3,11]$ indicates that the vertical polarization of the electric field and on the other hand the electric field in [13] and the proposed work is parallel to the ground. Secondly, it can be observed from columns 3 and 4 that the proposed power divider has a unique feature of outputinput inverse polarity but output-output in-phase polarity. Thirdly, column 5 indicates that the proposed power divider has a bandwidth of $163 \%$ which is suitable for ultra-wideband communications.

\section{Conclusion}

A novel ultra-wideband horizontal polarized output-input inverse polarity pulse power divider based on the use of a SMA directly feeding asymmetric coplanar stripline phase 


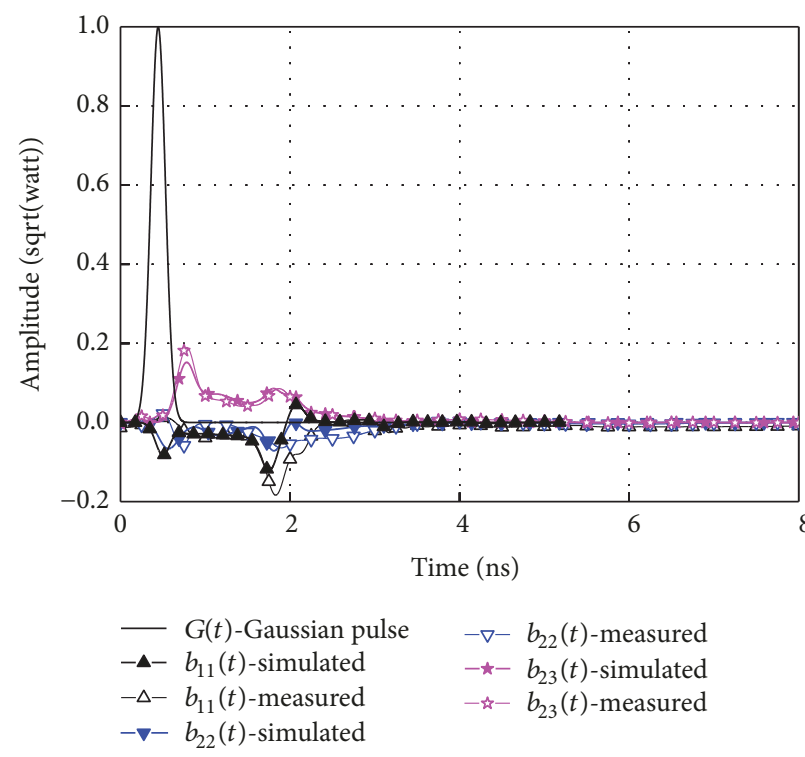

(a)

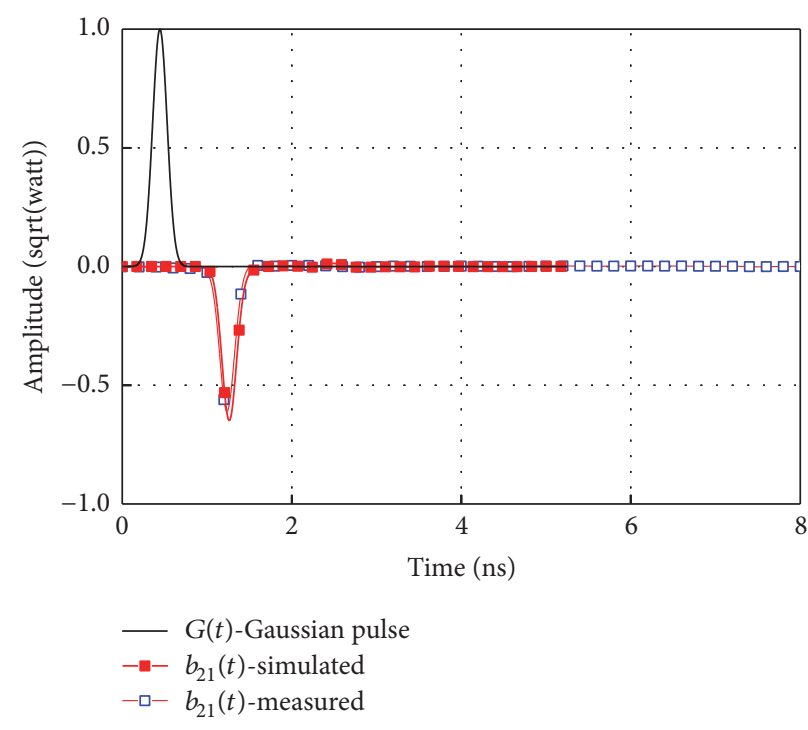

(b)

FIGURE 8: The simulated and measured performance in time domain. (a) The simulated input signal and the simulated and measured reflection signal and output signal and (b) the simulated input signal and simulated and measured signal at port 2.

TABLE 2: Comparison of the proposed power divider.

\begin{tabular}{lcccc}
\hline Reference & Polarization & $\begin{array}{c}\text { Input vs } \\
\text { Output }\end{array}$ & $\begin{array}{c}\text { Output vs } \\
\text { Output }\end{array}$ & $\begin{array}{c}\text { Band } \\
\text { width }\end{array}$ \\
\hline$[3]$ & Vertical & In Phase & In Phase & $90 \%$ \\
\hline$[11]$ & Vertical & $\begin{array}{c}\text { Out } \\
\text { of } \\
\text { Phase }\end{array}$ & $\begin{array}{c}\text { Out } \\
\text { of } \\
\text { Phase }\end{array}$ & $69 \%$ \\
\hline$[13]$ & Horizontal & $\begin{array}{c}\text { Out } \\
\text { of } \\
\text { Phase }\end{array}$ & $\begin{array}{c}\text { Out } \\
\text { of } \\
\text { Phase }\end{array}$ & $19 \%$ \\
\hline Proposed & Horizontal & $\begin{array}{c}\text { Out } \\
\text { of } \\
\text { Phase }\end{array}$ & In Phase & $163 \%$ \\
\hline
\end{tabular}

inverter is proposed. Phase inverter is firstly introduced and its performance in both frequency and time domain is evaluated. Then the proposed power divider was fabricated and measured. The simulated and measured results of the fabricated power divider agree well and show that the proposed power divider has good impedance matching, excellent amplitude and phase balance, and good isolation across the band from $0.4 \mathrm{GHz}$ to $4 \mathrm{GHz}$. According to its time domain results, output-input inversed polarity is observed. On the whole, all the measured results agree well with the simulated ones, demonstrating the feasibility and validity of the proposed power divider.

\section{Data Availability}

The data used to support the findings of this study are available from the corresponding author upon request.

\section{Conflicts of Interest}

The authors declare that there are no conflicts of interest related to this paper.

\section{Acknowledgments}

The authors would like to thank the staff of the State Key Laboratory of Millimeter Waves and thank AWR Corporation, A National Instruments Company, for making Analyst and Visual System Simulator available.

\section{References}

[1] X. Jiang, S. C. Ortiz, and A. Mortazawi, "A K a-band power amplifier based on the traveling-wave power-dividing/combining slotted-waveguide circuit," IEEE Transactions on Microwave Theory and Techniques, vol. 52, no. 2, pp. 633-639, 2004.

[2] H. Kobeissi and K. Wu, "Design technique and performance assessment of new multiport multihole power divider suitable for M(H)MIC's," IEEE Transactions on Microwave Theory and Techniques, vol. 47, no. 4, pp. 499-505, 1999.

[3] S. C. Hui, B. L. Ooi, H. Y. Fong, and B. Wu, "Broadband multilayer active-slot power divider," Microwave and Optical Technology Letters, vol. 41, no. 1, pp. 10-12, 2004.

[4] L. Álvarez, J. Portilla, M. L. De La Fuente, and E. Artal, "MMIC medium-power amplifier in $\mathrm{k}$ band with matching and power-divider/combiner networks implemented with the use of lumped elements," Microwave and Optical Technology Letters, vol. 33, no. 6, pp. 397-400, 2002.

[5] J. Li and Y. Zou, "Novel wilkinson power divider based on lefthanded transmission lines," Microwave and Optical Technology Letters, vol. 49, no. 3, pp. 712-715, 2007. 
[6] J.-C. Kao, Z.-M. Tsai, K.-Y. Lin, and H. Wang, "A modified wilkinson power divider with isolation bandwidth improvement," IEEE Transactions on Microwave Theory and Techniques, vol. 60, no. 9, pp. 2768-2780, 2012.

[7] S. W. Wong and L. Zhu, "Ultra-wideband power divider with good in-band splitting and isolation performances," IEEE Microwave and Wireless Components Letters, vol. 18, no. 8, pp. 518-520, 2008.

[8] K. Song, X. Ren, F. Chen, and Y. Fan, "Ultrawideband notchband power divider with bandpass response using defect microstrip structure," Microwave and Optical Technology Letters, vol. 56, no. 3, pp. 711-715, 2014.

[9] P. Wu, Y. Zhang, and Q. Zhang, "A novel wideband Wilkinson divider using parallel branch lines," Microwave and Optical Technology Letters, vol. 53, no. 4, pp. 781-783, 2011.

[10] T.-S. Dang, C.-W. Kim, and S.-W. Yoon, "Ultra-wideband power divider using three parallel-coupled lines and one shunt stub," IEEE Electronics Letters, vol. 50, no. 2, pp. 95-96, 2014.

[11] U. T. Ahmed and A. M. Abbosh, "Design of wideband singlelayer in-phase power divider using microstrip to slotline coupled structure," Microwave and Optical Technology Letters, vol. 57, no. 4, pp. 789-791, 2015.

[12] K. Song, Y. Fan, and X. Zhou, "Broadband multilayer in-phase power divider," IEEE Electronics Letters, vol. 44, no. 6, pp. 417419, 2008.

[13] L. Fan and K. Chang, "A 180。 out-of-phase power divider using asymmetrical coplanar stripline," IEEE Microwave and Guided Wave Letters, vol. 6, no. 11, pp. 404-406, 1996.

[14] S. Li, X. Yin, H. Zhao, and H. Qi, "Postwall slotline and its application in design of short-pulse tapered slot antennas," Institute of Electrical and Electronics Engineers. Transactions on Antennas and Propagation, vol. 63, no. 8, pp. 3400-3409, 2015. 


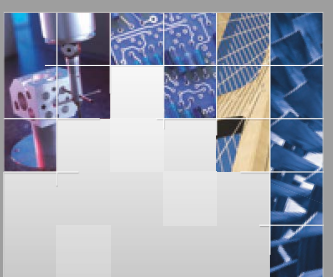

\section{Enfincering}
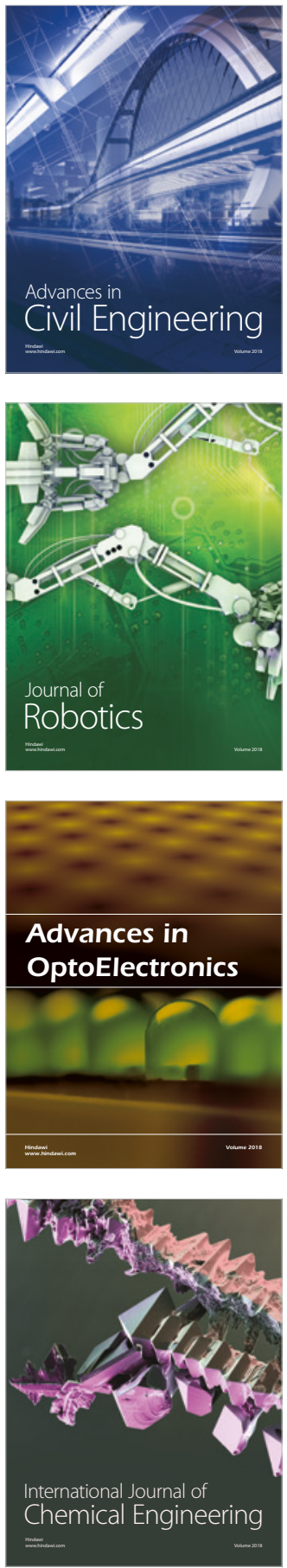

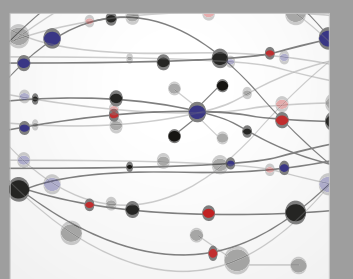

\section{Rotating \\ Machinery}

The Scientific World Journal

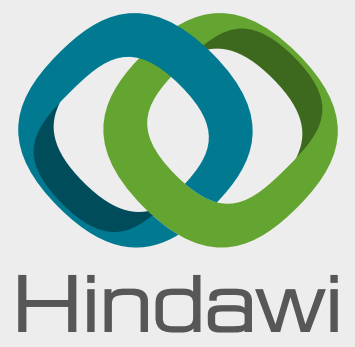

Submit your manuscripts at

www.hindawi.com
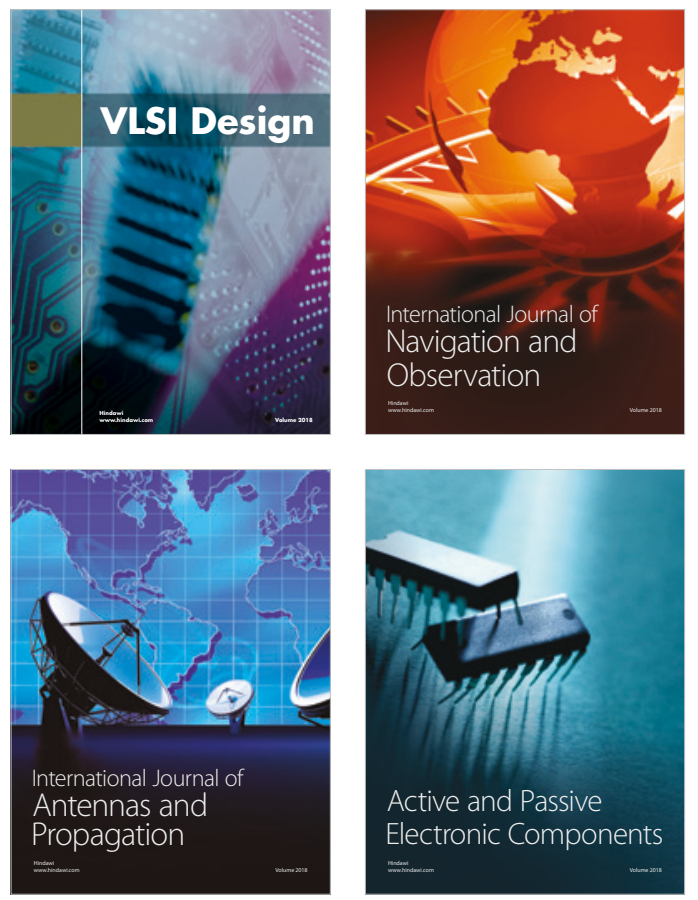
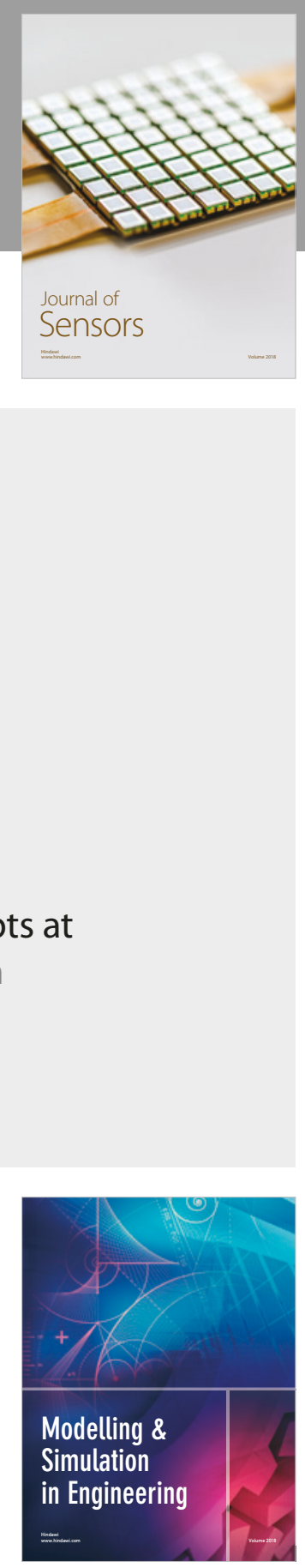

\section{Advances \\ Multimedia}
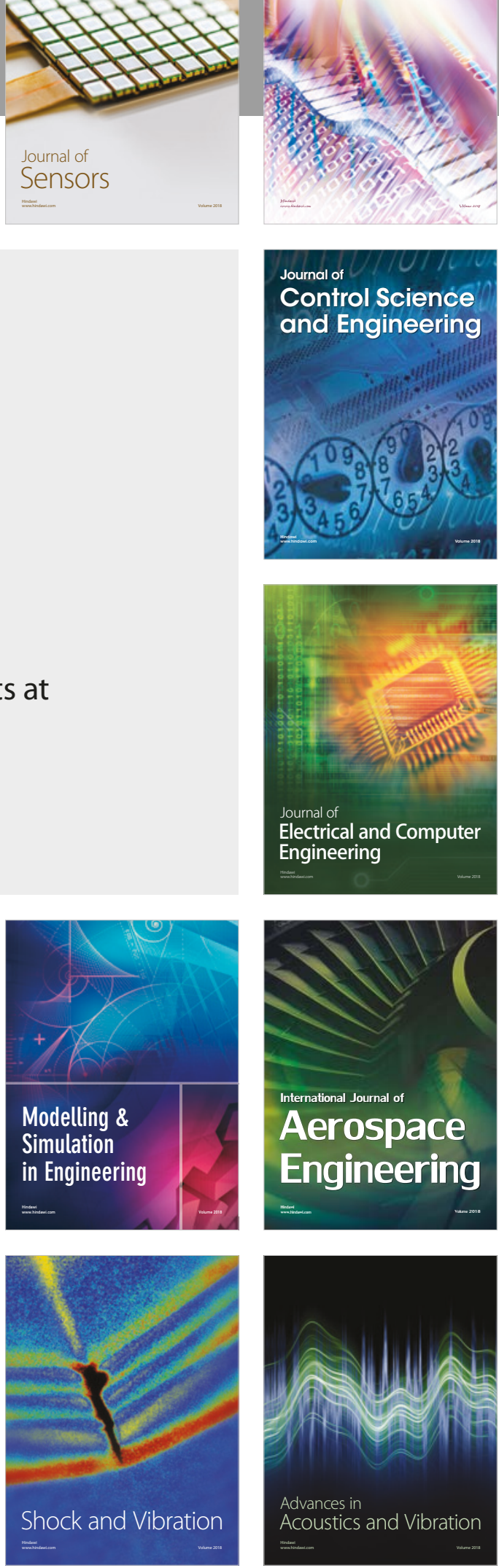